\title{
Journals on the Net: some sites reviewed
}

\author{
SUSAN BOOBIS \\ clo Hospital for Tropical Diseases, 4 St Pancras Way, London NW1 OPE
}

\section{Introduction}

Following the recent article on 'Leprosy and the Internet' by J. S. Gilbody (Lepr Rev, 1997; 68: 367-370), it was felt that readers of Leprosy Review might find it useful to have regular updates on what is available, not just in the area of leprosy, but in medicine generally. This is the first of these updates, and it reviews four websites operated by medical journals, the British Medical Journal, the Lancet, the New England Journal of Medicine and, last but not least, Leprosy Review's own website. The review concludes with some thoughts on the advantages and disadvantages of electronic journals for the developing world.

British Medical Journal (http://www.bmj.com/index.shtml)

The British Medical Journal has recently provided free access to all published articles on its website. In a recent Editorial, Tony Delamothe, BMJ's Web Editor, and journal Editor Paul Smith said: 'Three years ago, it was hard to find a medical journal on the internet. Now most have websites, providing selections from their paper journals in electronic form. .....the $B M J$ joins the Lancet and a host of specialist journals in taking the obvious next step: providing the full text of the paper journal online. Soon most other medical journals interested in their long term survival will follow suit.'

The $B M J$ 's website is attractively laid out, and easily accessible. No registration is required. Readers can browse through the current issue of the journal, or search for topics by keyword, date or volume and page number. If a search of the $B M J$ 's archives is unsuccessful, there is the opportunity to look in the websites of other journals. Readers can opt to have the Table of Contents e-mailed to them free each week, and may also request information only on topics in which they are interested - an attractive option for specialists in relatively rare topics such as leprosy!

The $B M J$ 's policy is to make the electronic journal their main route for publication, although they will continue to publish a paper version in tandem. They cite the advantages of virtually unlimited space on the Web, so that they can promise earlier publication of particularly interesting and topical articles. Use of the Web will also result in considerable savings in postal and printing charges.

At present, access to the site is free; however, the Editors recognize that eventually, as readers change from the paper to the electronic version of the journal, they will either have to charge a fee for access, or seek sponsorship. 
One encouraging sign is the fact that the BMJ Publishing Group are already thinking of how they might provide the developing world with access to their journals. A few lines of computer programming could allow free (or heavily discounted) access to computers from selected countries and, unlike discounts on paper subscriptions, the gesture would cost publishers nothing.

\section{Lancet (http://www.thelancet.com/)}

The Lancet's website is largely accessible to non-subscribers to the paper journal, but registration is required in order to use it, although there is no fee for registration. Users are presented with an on-screen registration form, asking for name, contact details, job and specialist interests. When this has been filled this in, the user can choose an on-screen name and password, which is needed to access the site in future.

The site has several areas. The Journal area enables the user to browse the current issue, supplements, back issues and press releases. The Discussion Groups provide a forum for subscribers to debate material published in The Lancet. Topics currently covered include tamoxifen and breast cancer, malaria and the UK National Health Service, but new subjects are constantly being introduced. The Arcade provides advertising, job opportunities, subscription details, links to other websites and media information. Information for Authors has instructions for submitting papers and contact numbers for Lancet staff. There is also a Search area, for locating articles on particular topics.

Subscribers to the paper journal have access to a special area in the Journal area, which contains the complete text of each article, but the 'free' area is quite comprehensive, and includes all the other facilities. It should be sufficient for most casual users.

The Lancet site is aimed more at Western European readers, and has not so far identified the developing world as a potential market.

\section{New England Journal of Medicine (http://www.nejm.org/content/index.asp)}

This journal's website also has two parts: a free, unrestricted area for all users, and a subscriber-only area. The subscriber-only area offers subscribers access to the complete text of the journal, including review articles, for all issues since 1993. Additional features for subscribers are a full-text search capability and a personal archive for saving links to articles and searches of interest. Using free software, subscribers can download articles and print them out in a format that is virtually identical to that of the printed pages.

For non-subscribers and casual users, the unrestricted area on the web site offers an electronic version of the Journal that includes all abstracts, editorials, letters to the editor, and book reviews, as well as classified advertisements and customer services. As with the Lancet and $B M J$, readers can opt to have the Table of Contents e-mailed to them free each week. They can also order offprints of individual articles for a fee of $\$ 10$ per article.

\section{Leprosy Review (http://www.lepra.org.uk/)}

This website is operated by the leprosy charity Lepra, and includes the Table of Contents, 
Editor's Choice and Editorials from Leprosy Review. Users have access to back issues, but there is currently no search facility. The possibility of providing free electronic access to the full text of all original articles in Leprosy Review is currently under review.

\section{Electronic journals and the developing world}

Subbiah Arunachalam, an Indian information scientist, believes that the Internet could widen the information gap between the developed and the developing world before it reduces it. Poor connections mean that even those with Internet access must spend hours downloading material that would take only minutes for those in the developed world who have the best access. Paradoxically, however, the Web could also prove more helpful for the information poor than any number of out of date medical journals and books sent to the developing world, where many libraries and institutions lack the resources to subscribe to current copies. Medical libraries in these countries would be far more likely to acquire computers with Internet access than to fill their shelves with vast quantities of information, much of which may not be relevant to their researchers.

Of the sites reported here, only the $B M J$ seems to have considered providing free, or reduced subscription, access to countries in the developing world. Hopefully, as electronic publishing becomes even more popular and more flexible, more journals will take up this option. 